\title{
Processes, mechanisms and utilization of organic soils
}

\author{
Lech Szajdak • Teodoro Miano
}

Received: 11 October 2008 / Accepted: 30 October 2008 / Published online: 19 November 2008

(C) Springer Science + Business Media B.V. 2008

\section{Preface and acknowledgements}

The present Special Issue "Processes, Mechanisms and Utilization of Organic Soils" contains selected papers presented in a special session at the European Geosciences Union (EGU) General Assembly held in Vienna, Austria in April 2007. The goal of this session was to discuss natural organic soils and sediments, peatlands (fens and raised bogs), mires, gyttja, as well as mucks, their main physico-chemical processes and their utilization.

Peat is a highly organic sediment (less than $25 \%$ of ash) whose physical, chemical and biological composition hardly depends on climate, topography, hydrology and geology. Humus in organic soils is composed of known and unknown chemical structures, whose impact on the physico-chemical properties (e.g., cation retention, metal chelation, hydrophobic interactions) and processes is of paramount importance. Peat is

Responsible Editor: Hans Lambers.

L. Szajdak $(\bowtie)$

Research Centre for Agricultural and Forest Environment, Polish Academy of Sciences,

Poznan, Poland

e-mail: szajlech@man.poznan.pl

T. Miano

Dip.to di Biologia e Chimica Agroforestale ed Ambientale, University of Bari,

Bari, Italy of interest to scientists in a variety of disciplines, such as plant ecology, organic geochemistry, soil science, coal geology, agronomy, and environmental sciences. Even though this topic was often considered in most of the agrochemistry, ecology, organic substrates, humic substances, landscape ecology and soil science meetings all around the world, the EGU meeting in Vienna has been the occasion to organize, for the first time ever, a specific comprehensive session on different aspects and approaches, with contributions from renowned experts of peat and organic soils sciences. Further, several young scientists involved in poster and oral presentations participated in very active and live debates during the meeting, promoting the session as a permanent forum of discussion, cooperation and exchange of scientific and professional experiences. During this session, the most recent progress and advancement in soil physics, soil chemistry, soil biochemistry, and soil microbiology of organic soils and their interactions with various components (organic vs. inorganic, natural vs. anthropogenic) have been extensively discussed.

The papers that emerged from the meeting in Vienna reveal that peat comprises either relatively unstable substances, whose reactivity contributes to its usefulness, or highly stable, recalcitrant fractions, both involved in the fate of organic and inorganic pollutants. Some investigations described the physiological activity of peat in stimulating and promoting plant growth. Among other topics raised and discussed were: changes of the carbon cycle in oligotrophic bogs in Western Siberia due to climate change 
and histosols as ecologically active constituent of peatlands.

In conclusion, the results presented during the session on Processes, Mechanisms and Utilization of Organic Soils are expected, i) to provide a better insight into chemical and physical properties and processes occurring in particular environments; and ii) to provide a stimulating background for future studies on this topic. As Guest Editors, we wish to express our gratitude to the authors for their presentations at the session and for their contribution to this issue. We are also very grateful to all colleagues involved in the reviewing process. 